\title{
Mendesain Soal Berbasis Masalah untuk Kemampuan Berpikir Kritis Matematis Calon Guru
}

\author{
Ekasatya A Afriansyah ${ }^{1}$, Tatang Herman², Turmudi ${ }^{3}$, dan Jarnawi A Dahlan ${ }^{4}$ \\ $1^{*}$ Pendidikan Matematika, Institut Pendidikan Indonesia \\ Jalan Pahlawan No 32 Sukagalih, Garut, Jawa Barat, Indonesia \\ 1*ekasatyafriansyah@institutpendidikan.ac.id \\ 2,3,4Pendidikan Matematika, Universitas Pendidikan Indonesia \\ Jalan Dr. Setabudhi No. 229 Bandung, Jawa Barat, Indonesia \\ 2tatangherman@upi.edu; ${ }^{3}$ turmudi@upi.edu; ${ }^{4 j a r n a w i @ u p i . e d u ~}$
}

Artikel diterima: dd-mm-yyyy, direvisi: dd-mm-yyyy, diterbitkan: dd-mm-yyyy

\begin{abstract}
Abstrak
Mahasiswa calon guru yang memiliki kemampuan berpikir kritis matematis diharapkan dapat memecahkan permasalahan yang berkaitan dengan konsep matematika ataupun konsep didaktiknya. Fokus keterampilan berpikir kritis matematis pada mahasiswa calon guru adalah kemampuan untuk mengidentifikasi permasalahan, mencari strategi, melakukan refleksi kembali, dan menganalisis permasalahan matematika. Penelitian ini bertujuan untuk mendesain soal berbasis masalah yang valid dalam meningkatkan kemampuan berpikir kritis matematis mahasiswa calon guru dalam berbagai materi pendidikan menengah. Penelitian ini mengambil jenis penelitian pengembangan, terdiri dari studi literatur, observasi, dan pengembangan soal. Kesimpulan dari penelitian ini hasil validasi expert menunjukan nilai validitas muka 80,35\% dan nilai validitas isi $86,85 \%$. Hal ini berarti soal-soal berbasis masalah untuk meningkatkan keterampilan berpikir kritis matematis dapat digunakan sebagai bahan pembelajaran dalam mata kuliah Kapita Selekta Matematika Pendidikan Dasar 1 untuk mahasiswa calon guru.

Kata Kunci: kemampuan berpikir kritis matematis, soal berbasis masalah, mahasiswa calon guru, penelitian pengembangan, validasi expert.
\end{abstract}

\section{Designing Problem Based Activity Questions for Prospective Teachers' Mathematical Critical Thinking Abilities}

\begin{abstract}
Prospective teacher students who can think critically mathematically are expected to be able to solve problems related to mathematical concepts or didactic concepts. The focus of mathematical critical thinking abilities on prospective teacher-students is the ability to identify problems, find strategies, reflect, and analyze mathematical problems. This study aims to design a valid and practical problem-based activity question to improve students' mathematical critical thinking abilities of prospective teachers in various secondary education materials. This research takes the type of Research and Development, consisting of a study of literature, observation, and development of questions. The conclusion from this study the results of expert validation showed an advance validity value of $80.35 \%$ and a value of content validity of $86.85 \%$. This means that problem-based activity questions to improve mathematical critical thinking abilities can be used as learning material in the Kapita Selekta Mathematics Basic Education 1 course for prospective teacher students.

Keyword: mathematical critical thinking skills, problem-based student questions, prospective teachers, Research and Development, expert validation.
\end{abstract}




\section{Pendahuluan}

Tujuan dari kurikulum 2013 adalah agar orang Indonesia memiliki kemampuan diri untuk menjadi individu yang produktif, taat, kreatif, dan inovatif, serta memiliki sikap yang dapat berkontribusi terhadap bangsa dan dunia (Sultika \& Hartijasti, 2017). Pembelajaran pada kurikulum 2013 berpusat pada siswa (Kuncara, Sujadi, \& Riyadi, 2016) agar siswa dapat mandiri dalam menguasai kompetensi dasar dan inti seluruh konsep materi. Oleh karena itu, guru dituntut untuk berpikir kritis dan kreatif (Afriansyah, 2017) serta perlu memiliki kemampuan dalam membuat berbagai macam persoalan (Chapman, 2015) yang dapat menuntut siswa untuk belajar mandiri. Matematika adalah mata pelajaran yang wajib diajarkan di seluruh level pendidikan di Indonesia (Faturohman \& Afriansyah, 2020), di mulai dari Sekolah Dasar (SD), Sekolah Menengah Pertama (SMP), sampai dengan Sekolah Menengah Atas (SMA).

Seorang guru bertujuan mengajarkan ilmu matematika untuk bekal bagi siswanya (Gravemeijer, dkk., 2017; Sukmawati, 2019) agar seluruh siswanya memiliki kemampuan berpikir logis, analitis, sistematis, kritis, dan kreatif yang dapat diterapkan di kehidupan mereka nantinya. Oleh karena itu, seorang calon guru perlu mengembangkan konsep matematika dan kemampuan berpikirnya (Abramovich, 2019; Afriansyah, dkk., 2019) dalam memecahkan permasalahan di sekolah maupun permasalahan yang berkaitan dengan kehidupan sehari-hari. Berdasarkan tujuan tersebut, mahasiswa calon guru perlu memiliki kemampuan berpikir tentang konsep matematika di atas siswanya nanti dalam hal belajar matematika.

Kegiatan proses belajar matematika dapat dikatakan tercapai apabila hasil belajar matematika siswa mencapai hasil di atas KKM (Eismawati, Koeswanti, \& Radia, 2019). Untuk itu, diperlukan dukungan dari seluruh komponen dalam proses pembelajaran. Salah satunya adalah bahan ajar yang biasa dipergunakan oleh guru. Bahan ajar ini merupakan seperangkat materi pembelajaran yang telah tersusun secara sistematis, biasa dipergunakan oleh guru dan siswa dalam proses pembelajaran (Supriatna \& Afriansyah, 2018). Bahan ajar dapat berupa buku, lembar kerja siswa, atau modul pembelajaran. Lembar kerja siswa atau lembar aktifitas adalah buku berisi tugas (Inan \& Erkus, 2017) yang dapat siswa kerjakan di sekolah ataupun di rumah. Lembar aktifitas juga berisi panduan bagi siswa yang digunakan untuk melakukan kegiatan penyelidikan atau pemecahan masalah (Trianto, 2010).

Merancang sistematika dan struktur lembar aktifitas (Nengsih \& Septia, 2017) perlu waktu yang tidak sebentar. Yang dimaksud dengan lembar aktifitas dalam penelitian ini adalah lembaran kegiatan siswa yang dirancang menggunakan pendekatan berbasis masalah (Herman, 2007) pada beberapa materi pendidikan 
menengah yang memuat masalah, kegiatan belajar, informasi dan latihan bagi siswa.

Lembar aktifitas yang dikembangkan berisikan berbagai soal dengan variasi permasalahan sehari-hari. Adapun lembar aktifitas ini diawali dengan menghadapkan siswa pada suatu permasalahan dalam kehidupan sehari-hari (Pamungkas \& Afriansyah, 2017), kemudian kegiatan yang dapat membimbing siswa menemukan konsep (Rengganis, 2018) agar siswa dapat menyelesaikan masalah, serta memberikan kesempatan siswa untuk menggunakan bahasanya sendiri (Ika, Dinawati, \& Nurcholif, 2012) dalam menyimpulkan hasil dari kegiatan yang dilakukan. Tujuan penelitian ini adalah untuk menghasilkan soal berbasis masalah pada beberapa materi pendidikan menengah. Rahayu dan Afriansyah (2015) membuat soal berbasis pada level kesulitannya, sementara itu, pada penelitian ini diharapkan soal berbasis masalah yang dibuat dapat lebih baik dari penelitian sebelumnya.

Beberapa teori belajar yang mendukung dalam pengembangan bahan ajar adalah Bruner (dalam Siregar E dan Nara $H$, 2010) mengusulkan teori free discovery learning, yaitu proses pembelajaran dapat berjalan dengan kritis dan kreatif apabila guru memberikan kesempatan pada siswanya untuk menemukan sesuatu (konsep, teori, definisi) sendiri melalui contoh-contoh yang dapat menggambarkan aturan tersebut. Selain itu, teori konstruktivis yang didasari oleh Glaserverd, Benntencourt dan Matthews (dalam Siregar E dan Nara H, 2010), mengemukakan bahwa pengetahuan yang dimiliki seseorang merupakan hasil konstruksi orang itu sendiri. Sementara Piaget (dalam Trianto, 2014), mengemukakan bahwa perkembangan kognitif sebagai suatu proses dimana anak secara anak secara aktif membangun sistem makna dan pemahaman realitas melalui pengalaman-pengalaman dan interaksi-interaksi mereka. Implikasinya dalam pembelajaran ketika guru memberikan informasi yang terkait dengan siswa dalam menggunakan konsep-konsep, memberikan waktu yang cukup untuk menemukan ide-ide dengan menggunakan pola berpikir formal (Afriansyah \& Dahlan, 2017).

Kurikulum 2013 menekankan pada dimensi pedagogik modern (Fuadi, Johar, \& Munzir, 2016) dalam pembelajaran melalui pendekatan ilmiah (Scientific Approach). Pendekatan ilmiah dalam Kurikulum 2013 lebih dikenal dengan pendekatan saintifik. Pembelajaran dengan pendekatan saintifik tidak hanya melihat skor akhir sebagai hasil akhir (Pouyamanesh \& Firoozeh, 2013), namun proses pembelajaran dipandang sangat penting. Oleh karena itu, pembelajaran dengan pendekatan saintifik menekankan pada keterampilan proses (Direktorat Jendral Pendidikan Menengah, 2014). 


\section{Metode}

Metode penelitian yang digunakan adalah metode penelitian dan pengembangan (Research and Development). Sugiyono (2014) mengemukakan bahwa metode penelitian dan pengembangan merupakan jenis penelitian yang diharapkan dapat menghasilkan suatu produk dan dapat menguji keefektifitasan produk tersebut. Model pengembangan yang digunakan di dalam penelitian ini diadaptasi dari model pengembangan Borg \& Gall (1983), dimodifikasi menjadi lima langkah utama, yaitu: (1) studi pendahuluan; pengembangan produk; (3) validasi ahli dan revisi; (4) uji coba lapangan; dan (5) produk akhir.
Subjek penelitian terdiri dari uji coba lapangan untuk mengetahui kelayakan dan keterbacaan soal berbasis masalah yang terdiri dari 32 orang mahasiswa calon guru semester 3 Program Studi Pendidikan Matematika IPI Garut.

Data yang diperoleh dalam penelitian ini merupakan data kualitatif dan kuantitatif. Data kualitatif diperoleh dari saran/masukan validator, hasil observasi, dan catatan lapangan (Nu'man, 2019). Sedangkan data kuantitatif diperoleh dari penilaian validator serta pengolahan data hasil uji coba bahan ajar (Rusnilawati \& Gustiana, 2017). Prosedur penelitian yang dilakukan dalam penelitian ini dapat dilihat pada Bagan 1 berikut:

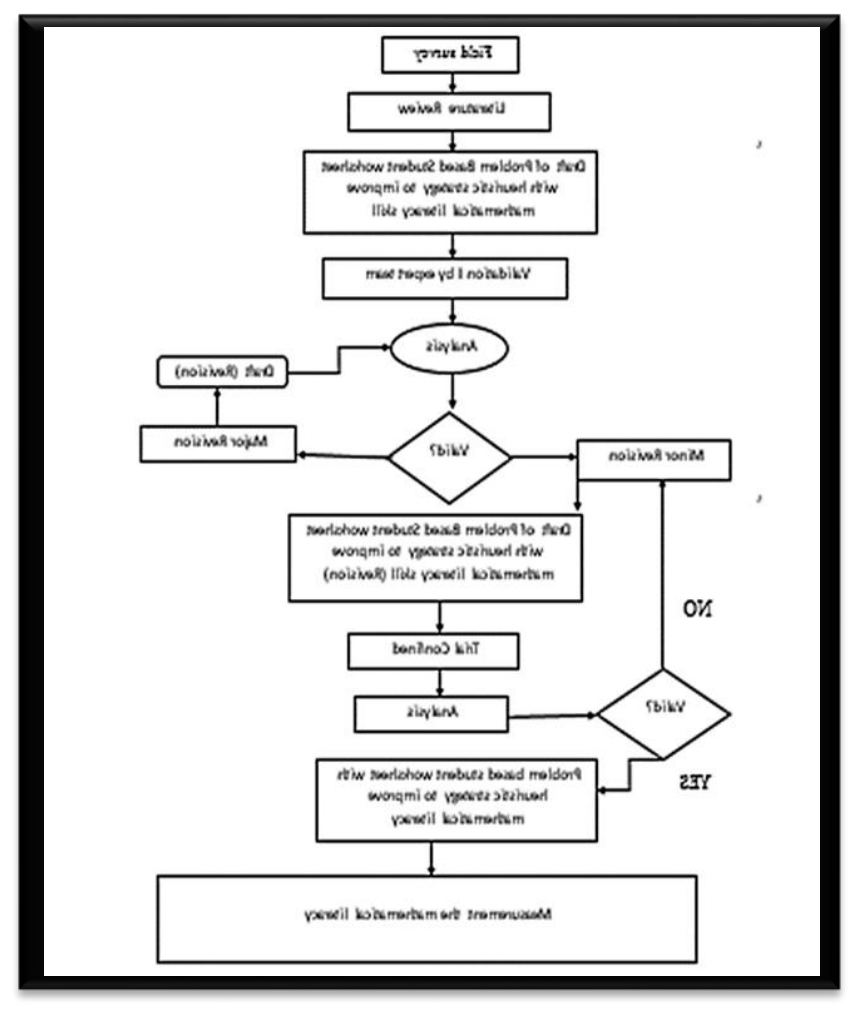

Bagan 1. Prosedur Penelitian. 


\section{Hasil dan Pembahasan}

Kegiatan yang dilakukan dalam mendesain soal meliputi studi pendahuluan, pengembangan produk, validasi dan revisi, uji coba - revisi, dan produk akhir berupa soal berbasis masalah.

\section{A. Studi Pendahuluan}

Peneliti melihat bahwa di dalam tahapan pemecahan masalah, guru memiliki kecenderungan untuk memberikan solusi permasalahan. Akibatnya siswa tidak terbiasa untuk melakukan pemikiran secara kritis khususnya siswa tidak terbiasa dalam memeriksa kembali kebenaran dari jawaban yang mereka peroleh. Hal itu disebabkan karena guru belum menerapkan tahapan berpikir kritis dalam pembelajaran dengan baik sehingga siswa memiliki kecenderungan untuk lebih tertarik pada hasilnya apa yang benar bukan prosesnya bagaimana.

Pada tahap analisis, dilakukan kajian terhadap karakterisitik mahasiswa calon guru Program Studi Pendidikan Matematika IPI Garut meliputi kemampuan mahasiswa, latar belakang pengetahuan mahasiswa dan tingkat perkembangan kognitif mahasiswa. Hasil analisis menyimpulkan bahwa kemampuan mahasiswa calon guru dalam pembelajaran matematika masih terbilang belum cukup. Tingkat perkembangan kognitif untuk seorang mahasiswa seharusnya sudah memahami masalah dalam bentuk verbal dan mampu menyelesaikan masalah kompleks dengan cara yang lebih baik (Slavin dalam Trianto, 2013).

Hasil analisis kajian dari beberapa penelitian relevan telah menunjukkan bahwa pengembangan bahan ajar ataupun soal mampu meningkatkan kemampuan berpikir kritis matematis mahasiswa calon guru (Soeyono, 2014; Maulana, 2019). Pada tahap penentuan Kompetensi Inti dan Kompetensi Dasar yang akan diambil dalam penelitian, maka dipilih beberapa materi pendidikan menengah secara acak.

\section{B. Pengembangan Produk}

Kegiatan yang dilakukan pada tahap ini adalah mendesain produk awal bahan ajar, dalam hal ini soal. Analisis konsep dilakukan melalui beberapa materi matematika yang akan dibahas, menentukan prototipe yang disesuaikan dengan syarat kelayakan soal; serta memuat aspek-aspek pendekatan berbasis masalah dan melatih siswa menyelesaikan masalah melalui tahapan proses berpikir kritis matematis. Hal ini sejalan dengan yang dilakukan oleh Gazali (2016) di dalam penelitiannya.

\section{Validasi Ahli dan Revisi}

Pada tahap ini, kegiatan yang dilakukan untuk mengetahui tingkat keterbacaan melalui validasi muka dan kesesuaian materi soal melalui validasi isi. Sejalan dengan yang dikemukakan oleh Nuryani (2016), revisi keterbacaan soal dilakukan 
terhadap keambiguan kalimat soal atau ketidaksesuaian pemilihan istilah yang akan menyulitkan siswa nantinya. Sementara revisi kesesuaian materi dilakukan terhadap kekurangan konsep atau ketidakcocokan soal dengan indikatir yang diinginkan.

Validitas muka melibatkan 21 orang, yaitu: 5 orang ahli (dosen S3), 7 orang teman sejawat (dosen S2), 3 orang guru matematika (S1), dan 6 orang mahasiswa. Tujuan validitas muka soal untuk melihat tingkat keterbacaan soal ditinjau dari tingkat pendidikannya. Berikut hasil validitas disajikan dalam Tabel 1 berikut:
Tabel 1.

Rekapitulasi Penilaian Keterbacaan Soal

\begin{tabular}{lcc|}
\hline $\begin{array}{l}\text { Kriteria } \\
\text { Keterbacaan Soal }\end{array}$ & $\begin{array}{c}\text { Perolehan } \\
\text { Skor (\%) }\end{array}$ & Kategori \\
\hline Ahli (dosen S3) & $82,91 \%$ & Sangat Baik \\
\hline $\begin{array}{l}\text { Teman Sejawat } \\
\text { (dosen S2) }\end{array}$ & $86,49 \%$ & Sangat Baik \\
\hline Guru (S1) & $93,88 \%$ & Sangat Baik \\
\hline Mahasiswa & $69,39 \%$ & Baik \\
\hline Rata-rata & $\mathbf{8 0 , 3 5 \%}$ & Sangat Baik \\
\hline
\end{tabular}

Berikut disajikan perhitungan lengkap validitas muka untuk soal kemampuan berpikir kritis matematis, sebagai berikut: (lihat tabel 2)

Tabel 2.

Rekapitulasi Lengkap Validitas Muka Soal Kemampuan Berpikir Kritis Matematis

\begin{tabular}{|c|c|c|c|c|c|c|c|c|c|c|c|c|c|}
\hline \multirow[b]{2}{*}{ No } & \multicolumn{11}{|c|}{ Soal } & \multirow[b]{2}{*}{ Jumlah } & \multirow[b]{2}{*}{ Persentase } \\
\hline & $1 a$ & $1 b$ & 2 & $3 a$ & $3 b$ & 4 & 5 & $6 a$ & $6 b$ & 7 & 8 & & \\
\hline 1 & 4 & 4 & 4 & 4 & 4 & 4 & 2 & 4 & 4 & 4 & 2 & 40 & 72.73 \\
\hline 2 & 3 & 5 & 5 & 3 & 4 & 3 & 2 & 5 & 2 & 5 & 5 & 42 & 76.36 \\
\hline 3 & 3 & 5 & 3 & 5 & 5 & 5 & 5 & 5 & 5 & 5 & 4 & 50 & 90.91 \\
\hline 4 & 4 & 4 & 4 & 4 & 3 & 5 & 5 & 4 & 4 & 5 & 5 & 47 & 85.45 \\
\hline 5 & 5 & 3 & 5 & 5 & 5 & 3 & 5 & 5 & 5 & 5 & 3 & 49 & 89.09 \\
\hline 6 & 4 & 4 & 4 & 5 & 5 & 4 & 4 & 5 & 5 & 4 & 5 & 49 & 89.09 \\
\hline 7 & 5 & 4 & 5 & 5 & 5 & 4 & 5 & 5 & 5 & 5 & 4 & 52 & 94.55 \\
\hline 8 & 4 & 4 & 5 & 5 & 5 & 5 & 5 & 4 & 5 & 5 & 5 & 52 & 94.55 \\
\hline 9 & 4 & 4 & 4 & 4 & 4 & 4 & 4 & 4 & 4 & 4 & 4 & 44 & 80.00 \\
\hline 10 & 5 & 3 & 3 & 3 & 5 & 5 & 5 & 5 & 5 & 5 & 3 & 47 & 85.45 \\
\hline 11 & 3 & 4 & 2 & 4 & 3 & 3 & 3 & 2 & 4 & 4 & 3 & 35 & 63.64 \\
\hline 12 & 5 & 5 & 5 & 5 & 5 & 5 & 5 & 5 & 5 & 4 & 5 & 54 & 98.18 \\
\hline 13 & 3 & 3 & 3 & 4 & 4 & 3 & 3 & 3 & 3 & 3 & 3 & 35 & 63.64 \\
\hline 14 & 5 & 5 & 5 & 4 & 2 & 5 & 5 & 5 & 4 & 5 & 5 & 50 & 90.91 \\
\hline 15 & 5 & 5 & 5 & 5 & 4 & 5 & 4 & 5 & 5 & 5 & 5 & 53 & 96.36 \\
\hline 16 & 4 & 4 & 4 & 4 & 3 & 4 & 3 & 2 & 4 & 4 & 4 & 40 & 72.73 \\
\hline 17 & 3 & 3 & 4 & 4 & 4 & 4 & 3 & 4 & 3 & 3 & 4 & 39 & 70.91 \\
\hline 18 & 3 & 3 & 4 & 4 & 4 & 4 & 3 & 4 & 3 & 4 & 4 & 40 & 72.73 \\
\hline 19 & 4 & 3 & 5 & 4 & 4 & 3 & 2 & 3 & 2 & 4 & 2 & 36 & 65.45 \\
\hline 20 & 4 & 3 & 4 & 3 & 4 & 2 & 2 & 3 & 2 & 4 & 2 & 33 & 60.00 \\
\hline 21 & 4 & 4 & 4 & 3 & 5 & 3 & 4 & 4 & 3 & 4 & 3 & 41 & 74.55 \\
\hline Jumlah & 84 & 82 & 87 & 87 & 87 & 83 & 79 & 86 & 82 & 91 & 80 & 928 & 1687.27 \\
\hline Rata-rata & 4 & 3.9 & 4.14 & 4.14 & 4.14 & 3.95 & 3.76 & 4.1 & 3.9 & 4.33 & 3.8 & 44.2 & 80.35 \\
\hline
\end{tabular}


Revisi produk awal dilakukan berdasarkan saran/masukan dari 21 orang validator muka. Melalui saran/masukan validator tersebut, peneliti melakukan beberapa perbaikan, yaitu:

a) Memperjelas tulisan pada gambar. Sebelumnya tulisan keterangan gambar tiap bangun datar terlalu kecil sehingga tidak dapat terbaca dengan jelas.

b) Mengganti kalimat tanya. Semula mahasiswa diminta mencari siapakah yang benar tentang perbedaan pendapat direvisi menjadi pernyataan mana yang benar sehingga mahasiswa tidak akan terlalu fokus ke orangnya tetapi pendapatnya.

c) Memperjelas pertanyaan yang dimaksud pada beberapa soal. Sebelumnya beberapa pertanyaan yang berkaitan dengan gambar belum terlalu jelas sehingga dapat membingungkan mahasiswa yang mengisinya.

d) Merubah istilah-istilah yang lebih cocok dengan $\mathrm{KBBI}$, contoh: horizontal menjadi horizontal.

e) Mengganti keterangan umum yang berkaitan dengan gambar dengan keterangan yang lebih spesifik.

f) Memperbaiki struktur kalimat pertanyaan yang berbentuk soal cerita supaya tidak terlihat rumit. g) Menuliskan kalimat pertanyaan yang lebih baku.

h) Lebih konsisten terhadap penulisan istilah pada beberapa pertanyaan.

i) Memperbaiki beberapa kalimat tanya pada soal. Sebelumnya kalimat tanya bersifat kalimat aktif dirubah menjadi kalimat pasif.

j) Menyusun kembali diksi beberapa kalimat menjadi kalimat dengan diksi yang tepat.

Validitas isi melibatkan 13 orang, yaitu: 4 orang ahli (dosen S3), 5 orang teman sejawat (dosen S2), dan 4 orang guru matematika (S1). Tujuan validitas muka soal untuk melihat tingkat kesesuaian materi soal ditinjau dari tingkat pendidikannya. Berikut hasil validitas disajikan dalam Tabel 3 berikut:

Tabel 3.

Rekapitulasi Penilaian Keterbacaan Soal

\begin{tabular}{lcl|}
\hline $\begin{array}{l}\text { Kriteria } \\
\text { Keterbacaan Soal }\end{array}$ & $\begin{array}{c}\text { Perolehan } \\
\text { Skor }(\%)\end{array}$ & Kategori \\
\hline Ahli (dosen S3) & $83,64 \%$ & Sangat Baik \\
\hline $\begin{array}{l}\text { Teman Sejawat } \\
\text { (dosen S2) }\end{array}$ & $88,73 \%$ & Sangat Baik \\
\hline Guru (S1) & $87,73 \%$ & Sangat Baik \\
\hline Rata-rata & $\mathbf{8 6 , 8 5 \%}$ & Sangat Baik \\
\hline
\end{tabular}

Berikut disajikan perhitungan lengkap validitas isi untuk soal kemampuan berpikir kritis matematis, sebagai berikut: (lihat tabel 4) 
Tabel 4.

Rekapitulasi Lengkap Validitas Isi Soal Kemampuan Berpikir Kritis Matematis

\begin{tabular}{|c|c|c|c|c|c|c|c|c|c|c|c|c|c|}
\hline \multirow[b]{2}{*}{ No } & \multicolumn{11}{|c|}{ Soal } & \multirow[b]{2}{*}{ Jumlah } & \multirow[b]{2}{*}{ Persentase } \\
\hline & $1 a$ & $1 b$ & 2 & $3 a$ & $3 b$ & 4 & 5 & $6 a$ & $6 b$ & 7 & 8 & & \\
\hline 1 & 4 & 4 & 4 & 4 & 4 & 4 & 2 & 4 & 4 & 4 & 4 & 42 & 76.36 \\
\hline 2 & 5 & 5 & 5 & 3 & 5 & 5 & 5 & 5 & 5 & 5 & 4 & 52 & 94.55 \\
\hline 3 & 4 & 3 & 4 & 2 & 3 & 3 & 5 & 4 & 3 & 3 & 3 & 37 & 67.27 \\
\hline 4 & 5 & 5 & 5 & 4 & 5 & 4 & 5 & 5 & 5 & 5 & 5 & 53 & 96.36 \\
\hline 5 & 4 & 4 & 4 & 5 & 5 & 4 & 4 & 5 & 5 & 4 & 5 & 49 & 89.09 \\
\hline 6 & 4 & 5 & 5 & 5 & 5 & 5 & 5 & 4 & 5 & 5 & 5 & 53 & 96.36 \\
\hline 7 & 4 & 4 & 4 & 4 & 5 & 4 & 5 & 5 & 5 & 5 & 4 & 49 & 89.09 \\
\hline 8 & 4 & 5 & 2 & 4 & 2 & 3 & 4 & 4 & 4 & 4 & 4 & 40 & 72.73 \\
\hline 9 & 5 & 5 & 5 & 5 & 5 & 4 & 5 & 5 & 5 & 4 & 5 & 53 & 96.36 \\
\hline 10 & 3 & 4 & 4 & 4 & 3 & 3 & 3 & 4 & 4 & 4 & 5 & 41 & 74.55 \\
\hline 11 & 5 & 5 & 5 & 4 & 3 & 5 & 5 & 5 & 5 & 4 & 5 & 51 & 92.73 \\
\hline 12 & 5 & 5 & 5 & 5 & 5 & 5 & 4 & 5 & 5 & 5 & 5 & 54 & 98.18 \\
\hline 13 & 4 & 4 & 5 & 4 & 5 & 4 & 4 & 5 & 4 & 4 & 4 & 47 & 85.45 \\
\hline Jumlah & 56 & 58 & 57 & 53 & 55 & 53 & 56 & 60 & 59 & 56 & 58 & 621 & 1129.09 \\
\hline Rata-rata & 4.31 & 4.46 & 4.38 & 4.08 & 4.23 & 4.08 & 4.31 & 4.62 & 4.5 & 4.31 & 4.5 & 47.77 & 86.85 \\
\hline
\end{tabular}

Merevisi produk awal yang berdasarkan saran/masukan dari 13 orang validator isi. Melalui saran/masukan validator, peneliti melakukan beberapa perbaikan, yaitu:

a) Merubah pertanyaan ataupun pengantar soal dikarenakan kurang sesuai dengan indikator yang diinginkan.

b) Mengganti bentuk pertanyaan guna menaikkan level soal.

c) Mengganti redaksi pengantar soal supaya tidak menimbulkan keambiguan.

d) Memperjelas berapa banyak jawaban yang perlu dibuat pada soal tertentu.

e) Mengganti redaksi soal agar lebih sesuai dengan indikator soalnya.

\section{Uji coba lapangan}

Uji coba dilakukan terhadap 32 mahasiswa calon guru semester 2 Program
Studi Pendidikan Matematika IPI Garut, terdiri dari 10 mahasiswa calon guru dengan kemampuan rendah, 12 mahasiswa calon guru dengan kemampuan sedang, dan 10 mahasiswa calon guru dengan kemampuan tinggi.

Hasil uji coba soal kemampuan berpikir kritis diperoleh 4 dari 11 soal tidak valid, sehingga perlu adanya kajian yang lebih mendalam lagi. Seperti halnya dalam penelitian Arifin (2017), beberapa soal yang tidak valid tersebut akan dipertimbangkan untuk dihilangkan atau diperbaiki/diganti dengan soal baru yang selanjutnya akan diujicobakan kembali. Keputusan tersebut tidak akan kami bahas disini. Berikut hasil perhitungan validasi soal uji coba kemampuan berpikir kritis matematis, yaitu: (lihat tabel 5) 
Tabel 5.

Rekapitulasi Uji Validitas Soal Kemampuan Berpikir Kritis Matematis

\begin{tabular}{|c|c|c|c|c|}
\hline Nomor Soal & Koefisien Korelasi & thitung & ttabel & Keterangan \\
\hline $1 \mathrm{a}$ & 0.6687 & 3.5729 & 2.03806 & Valid \\
\hline $1 \mathrm{~b}$ & 0.4536 & 2.4343 & 2.03806 & Valid \\
\hline 2 & 0.4436 & 2.3806 & 2.03806 & Valid \\
\hline $3 \mathrm{a}$ & 0.0575 & 0.3099 & 2.03806 & Tidak Valid \\
\hline $3 \mathrm{~b}$ & 0.1419 & 0.7641 & 2.03806 & Tidak Valid \\
\hline 4 & -0.2218 & -1.1936 & 2.03806 & Tidak Valid \\
\hline 5 & 0.4164 & 2.2359 & 2.03806 & Valid \\
\hline $6 \mathrm{a}$ & 0.3269 & 1.7569 & 2.03806 & Tidak Valid \\
\hline $6 \mathrm{~b}$ & 0.5931 & 3.1744 & 2.03806 & Valid \\
\hline 7 & 0.6833 & 3.6499 & 2.03806 & Valid \\
\hline 8 & 0.5431 & 2.9099 & 2.03806 & Valid \\
\hline
\end{tabular}

\section{E. Produk akhir}

Penelitian ini memiliki produk akhir, tentunya adalah sekumpulan soal kemampuan berpikir kritis yang sudah lolos dari validasi expert (validitas muka dan isi) dan validasi statistika. Dihasilkan 7 nomor yang siap untuk diterapkan dalam suatu penelitian. Pelaporan penelitiannya akan didiskusikan di lain kesempatan.

Rencana penelitian berikutnya melalui proses pembelajaran akan diterapkan soal berbasis masalah, diamati oleh 3 orang observer untuk melihat kemampuan dosen mengelola pembelajaran dan bertugas pula mengamati aktivitas mahasiswa.

\section{Penutup}

Berdasarkan hasil penelitian dan desain soal berbasis masalah dapat disimpulkan bahwa (1) Hasil lembar validasi expert sudah menunjukkan kategori sangat baik pada validitas muka ataupun validitas isi, dengan skor validitas muka adalah 80,35\% dan skor validitas isi adalah 86,85\%; (2) Hasil dari uji coba 11 soal dengan pengolahan uji validitas secara statistika, diperoleh 7 soal valid dan dapat dipergunakan langsung pada penelitian; (3) Seorang calon guru hendaknya belajar banyak dari penelitian ini supaya kedepannya saat menjadi guru yang sebenarnya, mereka tidak lupa untuk terus berinovasi dalam mendesain bahan ajar yang sesuai dengan karakter siswanya dan tuntutan dari kurikulum.

Penelitian ini memiliki keterbatasan, yaitu subjek penelitian hanya dilakukan di satu perguruan tinggi, yaitu salah satu perguruan tinggi di kota Garut. Sangat terbuka peluang bagi peneliti lainnya untuk meneliti di institusi lain, serta dapat pula meneliti pada level lainnya, seperti SD, SMP, ataupun SMA.

\section{DAfTAR PUStaka}

Abramovich, S., Grinshpan, A. Z., \& Miligan, D. L. (2019). Teaching 
Mathematics through Concept Motivation and Action Learning. Hindawi: Education Research International, Volume 2019, Article ID 3745406, 1-13.

Afriansyah, E. A. (2017). Problem Posing merupakan Kemampuan Matematis. Mosharafa: Jurnal Pendidikan Matematika, 6(1), 163-180.

Afriansyah, E. A., \& Dahlan, J. A. (2017). Design Research in Fraction for Prospective Teachers. the 5th SEA-DR (South East Asia Development Research) International Conference 2017 (SEADRIC 2017). Advances in Social Science, Education, 100, 91-97.

Afriansyah, E. A., Puspitasari, N., Luritawaty, I. P., Mardiani, D., \& Sundayana, R. (2019). The analysis of mathematics with ATLAS. ti. Journal of Physics: Conference Series, 1402(7), 077097.

Arifin, Z. (2017). Kriteria Instrumen dalam suatu Penelitian. Jurnal THEOREMS (The Original Research of Mathematics), 2(1), 28-36.

Borg \& Gall. (1983). Education Research. New York: Longman.

Chapman, O. (2015). Mathematics teachers' knowledge for teaching problem solving. LUMAT, 3(1), 19-36.

Direktorat Jendral Pendidikan Menengah. (2014). Pembelajaran Matematika Melalui Pendekatan Saintifik. Jakarta: Kemdikbud.

Eismawati, E., Koeswanti, H. D., \& Radia, E. H. (2019). Peningkatan hasil belajar matematika melalui model pembelajaran problem based learning (PBL) siswa kelas 4 SD. Jurnal Mercumatika: Jurnal Penelitian Matematika dan Pendidikan Matematika, 3(2), 71-78.

Faturohman, I., \& Afriansyah, E. A. (2020). Peningkatan Kemampuan Berpikir Kreatif Matematis Siswa melalui Creative Problem Solving. Mosharafa: Jurnal Pendidikan Matematika, 9(1), 107-118.

Fuadi, R., Johar, R., \& Munzir, S. (2016). Peningkatkan Kemampuan Pemahaman dan Penalaran Matematis melalui Pendekatan Kontekstual. Jurnal Didaktika Matematika, 3(1), 47-54.

Gazali, R. Y. (2016). Pengembangan Bahan Ajar Matematika untuk Siswa SMP Berdasarkan Teori Belajar Ausubel. Pythagoras: Jurnal Pendidikan Matematika, 11(2), 182-192.

Gravemeijer, K., Stephan, M., Julie, C., Lin, F., \& Ohtani, M. (2017). What Mathematics Education May Prepare Students for the Society of the Future?. Int J of Sci and Math Educ, 15(Suppl 1), S105-S123.

Herman, T. (2007). Pembelajaran Berbasis Masalah untuk Meningkatkan Kemampuan Penalaran Matematis Siswa SMP. Cakrawala Pendidikan, XXVI(1). 41-62.

Ika, Dinawati, T., \& Nurcholif, D. S. L. (2012). Penerapan Pembelajaran Realistic Mathematics Education 
(RME) untuk Meningkatkan Aktivitas dan Hasil Belajar Siswa. Kadikma, 3(3), 133-146.

Inan, C., \& Erkus, S. (2017). The Effect of Mathematical Worksheets Based on Multiple Intelligences Theory on the Academic Achievement of the Students in the 4th Grade Primary School. Universal Journal of Educational Research, 5(8), 13721377.

Kuncara, A. W., Sujadi, I., \& Riyadi. (2016). Analisis Proses Pembelajaran Matematika Berdasarkan Kurikulum 2013 pada Materi Pokok Peluang Kelas X SMA Negeri 1 Surakarta. Jurnal Elektronik Pembelajaran Matematika, 4 (3), 352-365.

Maulana. (2019). Mengembangkan kemampuan berpikir investigatif matematis calon guru SD melalui strategi MURRDERR. Current Research in Education: Conference Series Journal, 1(1), 1-11.

Nengsih, S., \& Septia. (2017). Pengembangan Lembar Kegiatan Siswa Berbasis Penemuan Terbimbing pada Materi Peluang untuk Siswa Kelas XI IPA SMA Adabiah 2 Padang. Mosharafa: Jurnal Pendidikan Matematika, 6(1), 163-180.

Nu'man, M. (2019). Pengembangan Bahan Ajar Statistika Penelitian Pendidikan Matematika. Jurnal Mercumatika: Jurnal Penelitian Matematika dan Pendidikan Matematika, 3(2), 114128.
Nuryani. (2016). Tingkat Keterbacaan Soal Wacana Ujian Nasional (UN) Tingkat Sma Mata Pelajaran Bahasa Indonesia Tahun Pelajaran 2013/2014. Kembara: Jurnal Keilmuan Bahasa, Sastra, dan Pengajarannya, 2(1), 57-66.

Pamungkas, Y., \& Afriansyah, E. A. (2017). Aptitude Treatment Interaction terhadap Kemampuan Pemahaman Matematis Siswa. Jurnal Pendidikan Matematika RAFA, 3(1), 122-130.

Pouyamanesh, J., \& Firoozeh, L. (2013). Compared the Learning Outcomes of Students with Math in High and Low Frustration Tolerance. Procedia Social and Behavioral Sciences, 84. $837-840$.

Rahayu, D. V., \& Afriansyah, E. A. (2015). Meningkatkan Kemampuan Pemecahan Masalah Matematik Siswa melalui Model Pembelajaran Pelangi Matematika. Mosharafa: Jurnal Pendidikan Matematika, 4(1), 29-37.

Rengganis, P. (2018). Efektifitas Lembar Kegiatan Siswa (LKS) Berbasis Pendekatan Realistic Mathematics Education (RME) Materi Statistika Pada Siswa Sekolah Menengah Pertama. Jurnal Pendidikan Tambusai, 2(6), 1838-1844.

Rusnilawati, \& Gustiana, E. (2017). Pengembangan Bahan Ajar Elektronik (BAE) Berbantuan Flipbook Berbasis Keterampilan Pemecahan Masalah Dengan Pendekatan CTL pada Pembelajaran Matematika Kelas V 
Sekolah Dasar. Profesi Pendidikan Dasar, 4(2), 190 - 202.

Siregar, E., \& Nara, H. (2010). Teori Belajar

dan Pembelajaran. Bogor: Ghalia Indonesia.

Soeyono, Y. (2014). Pengembangan Bahan

Ajar Matematika dengan Pendekatan

Open-ended untuk Meningkatkan

Kemampuan Berpikir Kritis dan Kreatif

Siswa SMA. Pythagoras: Jurnal

Pendidikan Matematika, 9(2), 205218.

Sugiyono. (2014). Metode Penelitian

Pendidikan Pendekatan Kuantitatif,

Kualitatif dan $R$ \& D. Bandung:

Alfabeta.

Sukmawati, R. (2019). Analisis kesiapan mahasiswa menjadi calon guru profesional berdasarkan standar kompetensi pendidik. Jurnal Analisa, 5(1), 95-102.

Sultika, B., \& Hartijasti, Y. (2017). Faktorfaktor yang mempengaruhi kreativitas dan orientasi inovasi di tempat bekerja. Jurnal Riset Bisnis dan Manajemen Tirtayasa (JRBMT), 1(2), 179-199.

Supriatna, R., \& Afriansyah, E. A. (2018). Kemampuan Pemahaman Matematis Peserta Didik melalui Cooperative Learning Tipe Pair Checks VS Problem Based Learning. JPMI (Jurnal Pendidikan Matematika Indonesia), 3(1), 1-6.

Trianto. (2014). Mendesain Model

Pembelajaran Inovatif-Progresif.

Konsep (Landasan dan
Implementasinya pada Kurikulum tingkat Satuan) Pendidikan. Kencana Prenada Media Grup. Jakarta.

\section{Riwayat Hidup PenUlis}

Ekasatya Aldila Afriansyah, M.Sc.

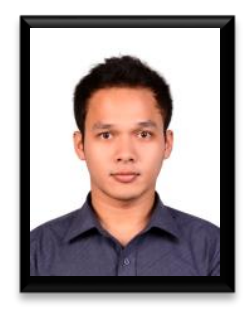

Lahir di Bandung, 4 April 1986. Dosen Tetap Yayasan STKIP Garut. Studi S1 Matematika Konsentrasi Statistika UPI, Bandung, lulus tahun 2009; S2 Pendidikan Matematika UNSRI-

Utrecht, lulus tahun 2012. UTRECHT, Palembang-

\section{Prof. Tatang Herman, M.Ed.}

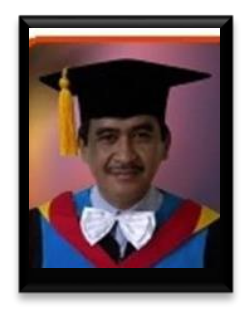

Dosen Pendidikan Matematika di Universitas Pendidikan Indonesia.

\section{Prof. Turmudi, M.Sc., M.Ed., Ph.D.}

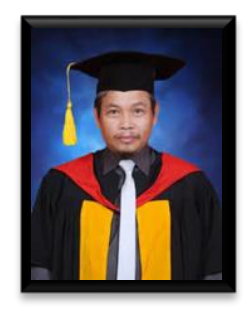

Dosen Pendidikan Matematika di Universitas Pendidikan Indonesia.

\section{Dr. Jarnawi Afgani Dahlan, M.Kes.}

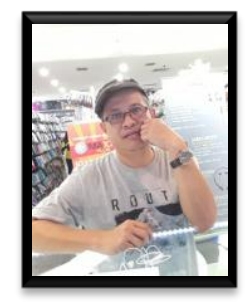

Dosen

Pendidikan Matematika di Universitas Pendidikan Indonesia. 